\title{
POST-OPERATIVE HEMORRHAGE IN SEPTOPLASTY WITH AND WITHOUT NASAL PACKING A COMPARATIVE STUDY AT OTORHINOLARYNGOLOGY DEPARTMENT OF PNS SHIFA HOSPITAL, KARACHI
}

\author{
Muhammad Fahad Wasim, Naeem Riaz, Sohail Aslam, Syed Muhammad Asad Shabbir Bukhari, Humza Mumtaz, \\ Iqbal Husain \\ Pakistan Naval Ship, Shifa Hospital, Karachi/National University of Medical Sciences (NUMS) Pakistan
}

\begin{abstract}
Objective: To do a comparison of the possibility of post-operative hemorrhage with and without nasal packing among the patients undergoing septoplasty.

Study Design: Comparative study.

Place and Duration of Study: Ear, nose, throat (ENT) Department, Pakistan Naval Ship, Shifa Hospital Karachi, from Apr 2019 to Oct 2019.

Methodology: Ninety two patients who underwent septoplasty due to deviation of nasal septum at ENT department of Pakistan Naval Ship Shifa were included in the analysis. Random division of patients was done in both the groups. Group one did not undergo nasal packing after the surgery and group two underwent nasal packing after the surgical procedure. Chi-square was used to see the difference in post-operative hemorrhage, headache, discomfort and septal perforation between the two groups.

Results: Out of 92 patients, $61(66.3 \%)$ patients were male while $31(33.7 \%)$ were female. Post operative bleeding was found in three $(6.5 \%)$ patients in group one while $13(28.2 \%)$ patients in group two had bleeding after the procedure. It was found that post-operative bleeding, headache and discomfort was statistically significant in the group 2, who's patients had nasal packing after the procedure of septoplasty due to deviated nasal septum.

Conclusion: Post-operative hemorrhage, headache and discomfort were more common among the patients with nasal packing as compared to those without nasal packing. Nasal packing after septoplasty should be discouraged without any obvious indication in the patients undergoing septoplasty.
\end{abstract}

Keywords: Hemorrhage, Nasal packing, Septoplasty.

This is an Open Access article distributed under the terms of the Creative Commons Attribution License (http://creativecommons.org/licenses/by/4.0), which permits unrestricted use, distribution, and reproduction in any medium, provided the original work is properly cited.

\section{INTRODUCTION}

Deviated nasal septum has been a common clinical condition encountered in the ENT outpatient departments all around the world ${ }^{1}$. It not only affect the appearance of individual but also prone him towards other clinical problems with troublesome symptoms². Medical treatment could only control these symptoms for a while but underlying deviation needs surgical correction as a definitive management ${ }^{3}$. Therefore surgical procedure done for this purpose has been the most widely performed surgery around the globe 4 .

Septoplasty involving the sub mucosal resection has been the surgery of choice for DNS in

Correspondence: Dr Muhammad Fahad Wasim, Resident ENT, PNS Shifa Hospital, Karachi Pakistan

Received: 01 Jan 2020; revised received: 07 Feb 2020; accepted: 11 Feb 2020 the recent past ${ }^{5}$. This surgery has been associated with better outcome both in terms of cosmetic results and symptomatic recovery ${ }^{6}$. Despite the effectiveness in terms of desired results this procedure has some untoward effects ${ }^{7}$. Common complications include headache, facial pain and discomfort after the surgery but they usually are self-limiting. Serious complications including septal hematoma or septal perforation have been rare 8,9 .

After the procedure of septoplasty, hemostasis has been an area of concern for the surgeons as this area has a rich blood supply. Methods commonly used for this purpose have been anterior nasal packing or applying a quilting suture. A study done in India comparing the results with and without nasal packing revealed that patients who underwent nasal packing after the proce- 
dure of septoplasty had more complications and spent more time in hospital clearly demonstrating the superiority of procedure without the nasal packing ${ }^{10}$.

In most of the cases septoplasty has not been a lifesaving procedure rather in some cases it is just performed for cosmetic purpose so patients usually are not ready to bear the untoward effects especially post-operative discomfort and bleeding. Few studies have been done in our country in this aspect which has declared that suturing has been superior to packing but these studies are quite old with less sample size. We therefore planned this study with the aim to compare the possibility of post-operative hemorrhage in septoplasty with and without nasal packing among the patients operated at PNS Shifa Hospital Karachi.

\section{METHODOLOGY}

This prospective comparative study was conducted at the ENT department of PNS Shifa Hospital Karachi, from April 2019 to October 2019 after written informed consent from patients and ethical approval from IREB committee with letter no: 001. Sample was gathered by using the universal sampling technique so all the patients fulfilling criterion in the given time were included in the study, therefore formal sample size calculation was not done with the calculator. Study of Ketcham et al, was used in this regard'. All patients between the age of 12 and 65 years undergoing septoplasty due to deviated nasal septum at ENT department of PNS Shifa hospital were included in the study. Patients were randomized into two groups by the lottery method. Patients less than 12 years of age or had poorly managed DM, IHD or those having any autoimmune disorder were not included. Pregnant patients or those with repeated procedure were not included in our analysis. Patients with active coagulopathy issues deranged INR, anemia of any type or any blood dyscrasias were also part of the exclusion criteria11-13. Patients with dependence of illicit drugs or sniffers were also not included in our analysis.
After carrying out all the base line and relevant investigations and anaesthetizing the patient with general anesthesia (anesthetist knew about the study but was blind), a hemi transfixion incision was typically utilized to open the caudal septum and following steps were performed:

Exposure of the divided septum.

Release of the forces that cause angulations.

Realignment of the septum.

Re-implantation of the crushed cartilage.

The turbinate reduction was typically performed using $4 \mathrm{MHz}$ radiofrequency generator Curis made by Sutter Medical. After the surgery patient either underwent nasal packing or quilt suturing depending upon the group allotted at the time of randomization when patients were briefed and recruited for this study ${ }^{14-17}$.

Group 1 did not undergo nasal packing. Quilting sutures are placed through the septum to hold the flaps together and to prevent hematoma formation. A 30 vicryl on a curved cutting needle is used. The slightly curved needle is straightened until a very slight curve remains at the tip. A knot is made at the end of the suture and the needle is passed through the septum from one nasal cavity to other starting from the anterior end of the middle turbinate to the vestibule where the knot was tied ${ }^{10}$.

Soframycin soaked ribbon gauze was used for packing group (group-2). Soframycin is framycetin sulphate which has antibiotic effect. Pack was removed after 48 hours of the procedure. Saline nasal irrigation and application of topical nasal decongestant and antibiotic ointment was advised for 2 weeks for both the groups. Oral antibiotic and antihistamine was given for 10 days.

Patients were observed for asked for the adverse effects immediately after the procedure as they recovered completely from anesthesia and till 48 hours after the procedure. All the complications were entered in a proforma which was designed and filled by the researchers of the study. 
SPSS-24 was used by the authors to carry out all the necessary data analysis for this study. Frequency and percentage for the quantitative variables was calculated especially the adverse effects faced by the patients after the procedure in both the groups. Pearson chi-square test (with $p$-values $\leq 0.05$ as significant) were performed to see the difference in headache, discomfort, septal peroration and post-operative bleeding in both the groups with and without the nasal packing.

\section{RESULTS}

Ninety two patients with confirmed diagnosis of DNS undergoing septoplasty fulfilled the inclusion and exclusion criteria for this study. They were randomly divided into two groups. Group one did not undergo nasal packing while group two patients underwent nasal packing after septoplasty. Out of 92 patients included in the final analysis $61(66.3 \%)$ were male and 31 $(33.7 \%)$ were female. Mean age of patients who underwent septoplasty and included in this analysis was $33.41 \pm 3.446$ years. Socio-demographic profile of the study participants has been summarized in table-I. Headache was the most common

Table-I: Characteristics of the study participants ( $n=92)$.

\begin{tabular}{|c|c|}
\hline Age (years) & \\
\hline Mean \pm SD & $33.41 \pm 3.446$ \\
\hline Range (min-max) & 15 years - 56 years \\
\hline \multicolumn{2}{|l|}{ Gender } \\
\hline Male & $61(66.3 \%)$ \\
\hline Female & $31(33.7 \%)$ \\
\hline \multicolumn{2}{|l|}{ Adverse Effects After Surgery } \\
\hline Headache & $23(25 \%)$ \\
\hline Discomfort & $22(23.9 \%)$ \\
\hline Septal hematoma & $04(4.3 \%)$ \\
\hline Septal perforation & $06(6.5 \%)$ \\
\hline Post-operative hemorrhage & $16(17.3 \%)$ \\
\hline
\end{tabular}

complication overall while septal hematoma was least reported (table-I). Post operative bleeding was found in three patients in group one while thirteen patients in group two had bleeding after the procedure. It was found that post-operative bleeding, headache and discomfort was statistically significant in the group 2, who had patients with nasal packing after the procedure of septoplasty due to deviated nasal septum (table-II).

Table-II: Relationship of different variables in two groups: pearson chi-square analysis

\begin{tabular}{|c|c|c|c|}
\hline $\begin{array}{l}\text { Socio- } \\
\text { Demographic } \\
\text { Factors } \\
\text { Total, } \mathrm{n}=92\end{array}$ & $\begin{array}{c}\text { Group } 1 \\
\text { Without } \\
\text { Nasal } \\
\text { Packing } \\
\end{array}$ & $\begin{array}{c}\text { Group } 2 \\
\text { With } \\
\text { Nasal } \\
\text { Packing } \\
\end{array}$ & $\begin{array}{c}p \text { - } \\
\text { value }\end{array}$ \\
\hline \multicolumn{4}{|l|}{ Headache } \\
\hline $\begin{array}{l}\text { No } \\
\text { Yes }\end{array}$ & $\begin{array}{l}40(86.9 \%) \\
06(13.1 \%)\end{array}$ & $\begin{array}{l}29(63.1 \%) \\
17(36.9 \%)\end{array}$ & 0.008 \\
\hline \multicolumn{4}{|l|}{ Discomfort } \\
\hline $\begin{array}{l}\text { No } \\
\text { Yes }\end{array}$ & $\begin{array}{l}40(86.9 \%) \\
06(13.1 \%)\end{array}$ & $\begin{array}{l}30(65.2 \%) \\
16(34.8 \%) \\
\end{array}$ & 0.015 \\
\hline \multicolumn{4}{|c|}{ Septal perforation } \\
\hline $\begin{array}{l}\text { No } \\
\text { Yes }\end{array}$ & $\begin{array}{l}41(89.1 \%) \\
05(10.9 \%) \\
\end{array}$ & $\begin{array}{c}45(97.8 \%) \\
01(2.2 \%) \\
\end{array}$ & 0.091 \\
\hline \multicolumn{4}{|c|}{ Post-operative hemorrhage } \\
\hline $\begin{array}{l}\text { No } \\
\text { Yes }\end{array}$ & $\begin{array}{c}43(93.4 \%) \\
03(6.6 \%)\end{array}$ & $\begin{array}{l}33(71.7 \%) \\
13(28.3 \%)\end{array}$ & 0.006 \\
\hline
\end{tabular}

\section{DISCUSSION}

Deviated nasal septum has been a common condition managed by ENT surgeons around the globe. Situation in our part of the world has been same and surgery for the correction of deviated nasal septum has been performed in routine. Septoplasty though a routine procedure which could be done in both local and general anesthesia; still associated with some complications and untoward effects. Sometimes it is the procedure which could lead to these complications and sometimes it is the postoperative hemostatic technique which could be responsible for the untoward effects. Local studies done by Iqbal et al and Muhammad et al in 2003 have also thrown light on this phenomenon but exact difference in terms of complications secondary to nasal packing or suturing has not been studied in detail $^{14,20}$. We therefore planned this study with the rationale to perform a comparison on postoperative bleeding among the patients undergoing septoplasty with and without standard nasal packing at PNS SHIFA hospital Karachi.

A retrospective analysis from Turkish setting concluded that post-operative pain was experienced more by the patient undergoing nasal 
packing after the septoplasty as compared to those undergoing suturing declaring trans-septal suturing technique as a preferred option in terms of patient satisfaction ${ }^{11}$. Mane et al, did an interesting analysis in this regard and came up with the conclusion that all untoward effects were found more in the nasal packing group and suturing procedure had less adverse effects especially in terms of pain and discomfort. They advocated that nasal packing should not be performed in routine and should be reserved for special cases only $^{12}$. A large meta-analysis in this aspect concluded that nasal packing has not been superior in preventing minor complications and providing a good overall quality of life. Simple suturing may be better option and associated with less chance of headache, bleeding, hematoma formation and patients feel more satisfied with just a suture as compared to suture along with nasal packing ${ }^{13}$. Our findings were not different from them and even from the local literature published long ago in this regard ${ }^{14,15}$.

Headache and discomfort emerged as most common overall untoward effects faced by the patients after the septoplasty. As they were common in both the groups so they might be associated more with the surgery instead of mode of hemostasis. Pearson chi-square however revealed that these two symptoms were significantly more common in the nasal packing group as compared to the group without nasal packing. This fact highlights that packing of nose after septoplasty has been more cumbersome for the patients and if suturing is done instead of packing it may be more convenient for the patients. These findings have also been concluded in the studies done in the past on this subject by Umihanic et al, in 2016 and Walikar et al, in 20118,10.

Primary outcome for this study was the presence of bleeding after the procedure and comparison in both the groups with and without the nasal packing. This comparative analysis revealed that hemorrhage was more common in packing group as compared to those without packing. Previous studies by Ketcahm et al in
2010 and Wang et al, in 2017 have reported the similar results in this regard ${ }^{9,13}$. These finding highlights that ritual of packing which has been used routinely after septoplasty is not doing much good to the patient, rather associated with more untoward effects including the hemorrhage.

Spetal perforation and spetal hematoma were the least reported complications and also were not found in any difference in any of the group of patients. This explains that packing has no effect on presence of these complications. Moreover the technique of septoplasty has been quite safe in our set up and serious complications occur at a very low rate. Literature globally has ascertained our findings. Especially studies of ketcham et al, Walikar et al, and Muhammad et al, published in 2010, 2011 \& 2003 respectively ${ }^{9,10,20}$.

Limitations of our study include lack of long term follow up. Sepsis and other causes of bleeding though were part of exclusion criteria but still it cannot be made fool proof and patients with bleeding were not further evaluated to look for exact cause of bleeding in both the groups. Moreover it cannot be hypothesized from the results that bleeding, headache and discomfort were more due to packing or due to actual surgical procedure or underlying other nasal or para nasal conditions. Studies with improved design and more sample size and duration may ascertain the findings in a much clearer way.

\section{CONCLUSION}

Post-operative hemorrhage, headache and discomfort were more common among the patients with nasal packing as compared to those without nasal packing. Nasal packing after septoplasty should be discouraged without any obvious indication in the patients undergoing septoplasty.

\section{CONFLICT OF INTEREST}

This study has no conflict of interest to be declared by any author.

\section{REFERENCES}

1. Del-Signore AG, Raithatha R, Senior BA. Nasal airway obstruction: Prevalence and anatomic contributors. Ear Nose Throat J 2018; 97(6): 173-76. 
2. Li WT, Chen XZ, Tu WJ. Psychopathological characteristics in patients with deviation of nasal septum: a preliminary analysis. Zhonghua Er Bi Yan Hou Tou Jing Wai Ke Za Zhi 2016; 51(9): 655-60.

3. Mumtaz H, Zubair UB, Raza SN. Comparison of intensity of chronic craniofacial pains of nasal/paranasal origin before and after the surgical management. J Coll Phy Surg Pak 2018; 28(10): 811.

4. Van Egmond MMHT, Rovers MM, Tillema AHJ, van Neerbeek N. Septoplasty for nasal obstruction due to a deviated nasal septum in adults: a systematic review. Rhinol 2018; 56(3): 195-08.

5. Kim DY, Nam SH, Alharethy SE, Jang YJ. Surgical outcomes of bony batten grafting to correct caudal septal deviation in septoplasty. JAMA Facial Plast Surg 2017; 19(6): 470-75.

6. Valsamidis K, Titelis K, Karkos P, Markou K, Constantinidis J, Triaridis S. Predictive factors of patients' general quality of life after nasal septoplasty. Eur Arch Otorhinol 2019; 276(2): 429-38.

7. Kuduban O, Bingol F, Budak A, Kucur C. The reason of dissatisfaction of patient after septoplasty. Eurasian J Med 2015; 47(3): 190-93.

8. Umihanic S, Brkic F, Osmic M, Umihanic S, Imamovic S. The Discrepancy Between Subjective and Objective Findings After Septoplasty. Med Arch 2016; 70(5): 336-38.

9. Ketcham AS, Han JK. Complications and management of septoplasty. Otolaryngol Clin North Am 2010; 43(4): 897-04.

10. Walikar BN, Rashinkar SM, Watwe MV, Fathima A, Kakkeri A. A comparative study of septoplasty with or without nasal packing. Ind J Otolaryngol Head Neck Surg 2011; 63(3): 247-48.

11. Cukurova I, Cetinkaya EA, Mercan GC, Demirhan E, Gumussoy
M. Retrospective analysis of 697 septoplasty surgery cases: packing versus trans-septal suturing method. Acta Otorhinolaryngol Ital 2012; 32(2): 111-14.

12. Mane RS, Patil B, Mohite A. Comparison of septoplasty with and without nasal packing and review of literature. Ind J Otolaryngol Head Neck Surg 2013; 65(Suppl-2): 406-08.

13. Wang WW, Dong BC. Comparison on effectiveness of transseptal suturing versus nasal packing after septoplasty: a systematic review and meta-analysis. Eur Arch Otorhinolaryngol 2017; 274(11): 3915-25.

14. Iqbal A, Rahman NM. Complications of the surgery for deviated nasal septum. J Coll Physian Surg 2003; 13(1): 565-68.

15. Awan MS, Iqbal M. Nasal packing after septoplasty: a randomized comparison of packing versus no packing in 88 patients. Ear Nose Throat J 2008; 87(11): 624-27.

16. Shah J, Roxbury CR, Sindwani R.Techniques in septoplasty: traditional versus endoscopic approaches. Otolaryngol Clin North Am 2018; 51(5): 909-17.

17. Most SP, Rudy SF. Septoplasty: Basic and Advanced Techniques. Facial Plast Surg Clin North Am 2017; 25(2): 161-69.

18. Kayahan B, Ozer S, Suslu AE, Ogretmenoglu O, Onerci M.The comparison of the quality of life and intranasal edema between the patients with or without nasal packing after septoplasty. Eur Arch Otorhinolaryngol 2017; 274(3): 1551-55.

19. Dubin MR, Pletcher SD. Postoperative packing after septoplasty: is it necessary? Otolaryngol Clin North Am 2009; 42(2): 279-85.

20. Muhammad IA, Rahman N. Complications of the surgery for deviated nasal septum. J Coll Physicians Surg Pak 2003; 13(10): 565-68. 